\title{
Numerical prediction of the flow structure inside components of industrial glass furnace systems
}

\author{
CARLO CRAVERO, DAVIDE DE DOMENICO, FRANC D. KENFACK, PHILIPPE J. LEUTCHA, \\ Department of Mechanical Engineering - DIME \\ Università di Genova \\ Via Montallegro 1, 16142 \\ ITALY
}

\begin{abstract}
An important aspect in the glass production industry is related to the heat recovery of the combustion gases. It is usually obtained throughout the use of well-tested technologies, such as regenerative towers with refractory material. For an effective heat recovery, a good distribution of the flow rate at the entrance of the chambers is crucial. The use of Computational Fluid Dynamics (CFD) allows the detailed analysis of the gas evolution during the process; the same would be impractical with experimental measurements, due to prohibitive ambient local conditions. The CFD approach during the design phase typically considers CAD geometries without the level of details related to technological features of the actual installed configuration (i.e. sharp edges vs rounded edges). A brand new built furnace has blunt edges in every connection between 3D walls of refractory blocks. The above edges will be rounded by the erosion-corrosion process due to the harsh chemical/mechanical/thermal environmental conditions inside the plant components (i.e. regenerative chambers, connecting ducts, furnace). The purpose of this work is to evaluate the influence of the geometrical details of the CAD (with focus on the edges connecting adjacent walls), due to technological or erosion aspects, on the flow structure in the furnace components.
\end{abstract}

Key-Words: - Computational Fluid Dynamics, industrial application, glass furnace

Received: September 18, 2019. Revised: April 14, 2020. Accepted: April 29, 2020. Published: May 15, 2020.

\section{Introduction}

Glass is a strategic material for modern society and this is the reason why the glass industry is recently in full expansion. However, this sector involves enormous energy consumption and produces high quantities of pollutants such as $\mathrm{CO} 2$, $\mathrm{CO}, \mathrm{NOx}$, etc. For these reasons, heat recovery from flue gases is essential to optimize the energy consumption and to limit the environmental impact. A widely used strategy involves the use of regenerative towers in refractory material. They allow to recover a large amount of the heat coming from the hot gases that leave the furnace at about $1400{ }^{\circ} \mathrm{C}$ and are discharged at a final temperature in the atmosphere of about $450{ }^{\circ} \mathrm{C}$. The heat is used to preheat the combustion air. This system, which stems from an 1850 patent, has been studied both experimentally and numerically [1-3] to demonstrate its high efficiency in heat recovery. In recent years, research has been oriented towards the development of innovative systems for the further recovery of heat from exhaust gases such as the preheating system of raw material [4], as well as the study of gas recirculation techniques to reduce NOx pollutant emissions [5-6-7-8].
In order to achieve a good effectiveness of the regenerative heat recovery system, it is necessary to provide a uniform flow distribution into the system starting from the chambers entrance [5-8].

In a new furnace configuration or in the exhaust configuration before demolition, it can be observed that the connection between walls is far from a sharp edge but there are blunt edges in the new furnaces and rounded edges in the eroded configuration. In Figure 1 two images of the same furnace in new conditions (left) and before demolition (right) are reported as a sample case of the actual technological conditions of the system. The above situation will certainly affect the flow solution details from the CFD analysis with respect to the reference "ideal" case of a CAD design

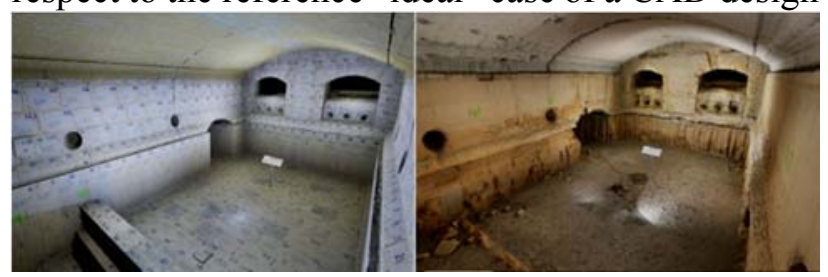

Fig.1. Glass furnace in new conditions (left) and before demolition (right) 
The CFD approach has proven to be an effective tool for flow simulation inside components of industrial systems [5-8] and also enhanced CFD approaches with specific models for gas emissivity [6] and real gas effects [9] have been developed, especially for heat transfer or combustion applications. The paper is aimed at verifying the effects of the geometrical details of the edges on the flow structure to understand if the standard CFD approach with sharp edges is actually representative of the flow structure and if the above geometrical details need to be taken into account into the CFD based design strategy for glass production plant components.

A numerical investigation on the impact of the geometry details on the flow modification has been performed with 2D analysis on the well known cases from literature of the Backward Facing Step (BFS) and the Forward Facing Step (FFS). After a preliminary set of simulations used to set and validate the numerical approach on the above reference cases [11-14], the geometry of the steps has been perturbed with the introduction of blunt or rounded edges. A detailed investigation on the turbulence closure has been conducted to understand its effect on flow recirculation extension prediction. The effects of blunt or rounded edges on flow recirculation extension have been investigated with the systematic application of the CFD model. The numerical approach has then been applied to a 3D configuration of a portion of the regenerative chamber with connecting duct (port neck) of a glass furnace to highlight the effects on the flow structure of the exhaust gases of blunt or rounded edges with respect to the reference case of sharp edges.

\section{CFD model setup: backward and forward facing steps}

In this section the attention is focused on the CFD approach set up in order to correctly simulate the reference cases of forward and backward facing steps. The analysis are aimed at the selection of the most appropriate turbulence closure and of the mesh type that will be applied to the 3D application to industrial components. The choice of the most suitable turbulence model for separation prediction was carried out by comparing three reference models, standard k-epsilon, k-epsilon realizable, k-omega SST, with data obtained from two literature references $[15,16]$. In the following the applications to the forward and backward cases are discussed separately. Unstructured meshes have been generated to discretize the domains using the commercial software Ansys ICEM CFD. All the simulations have been performed with the commercial code Ansys Fluent based on the finite volume method to numerically solve the RANS equations. Steady flow analysis have been performed.

The velocity and the total temperature at the inlet and the outflow condition at the outlet were set as boundary conditions. The walls are viscous and the fluid has been considered as an incompressible ideal gas.

\subsection{Backward Facing Step (BFS)}

In this case the experimental data of the paper by Driver and Seegmiller [15] and the corresponding associated database [17] have been considered as references. The simulations were carried out with the same Reynolds number $R e=36000$, referring to the height of the step h (eq.1), and maintaining the same geometric expansion ratio e, defined as the ratio between the $\mathrm{H} 2$ and $\mathrm{H} 1$ dimensions shown in the figure 2 .

$$
\begin{gathered}
R e_{h}=\frac{\rho U_{0} h}{\mu} \\
e=\frac{H 2}{H 1}
\end{gathered}
$$

An unstructured mesh with wall $\mathrm{y}+$ close to 1.0 is generated and a detail is shown in Fig. 3.

The BFS is characterized by a large separation downstream of the step with the presence of a recirculation bubble (Fig.2). To best simulate the recirculation area, a comparison was performed between three different turbulence models for the reattachment length (Xr) of the separation, the velocity profiles and the tangential stress; the same sections where the experimental data are available for detailed comparison have been considered. The evaluation of the reattachment point for the separation bubble has been carried out using the trend of the skin friction coefficient $\mathrm{Cf}$ (eq.3) on the lower wall, after the step. Xr will correspond to the distance from the step where the $\mathrm{Cf}$ changes its sign from negative to positive. Fig. 4 shows the curves of $\mathrm{Cf}$ for the three numerical simulations and the experimental case. The numerical data for the $\mathrm{Xr}$ are reported in Table 1. The k-epsilon Realizable and k-omega SST are the models that best approximate the measured value of the experimental reattachment length. The former underestimates the value while the latter overestimates it. The trend of the standard k-epsilon, instead, significantly underestimates Xr. 


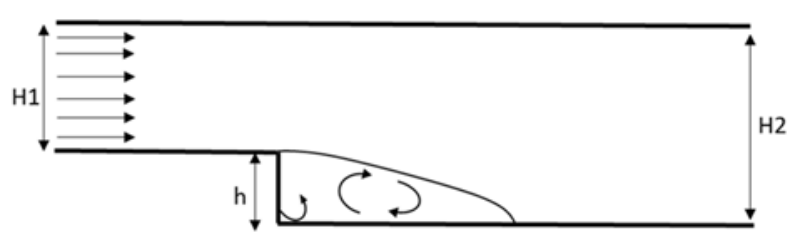

Figure 2. Backward Facing Step

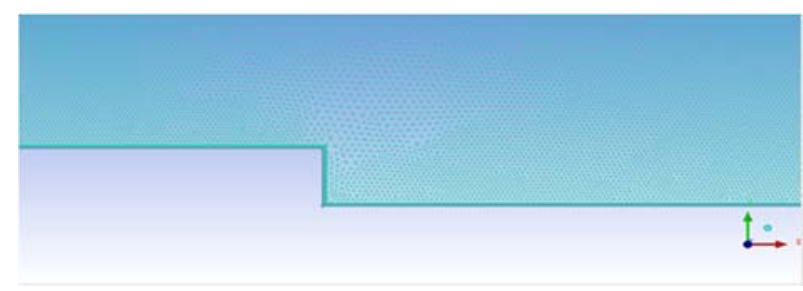

Figure 3. Unstructured mesh detail for the backward facing step

$$
C f=\frac{\tau_{w}}{\frac{1}{2} \rho v^{2}}
$$

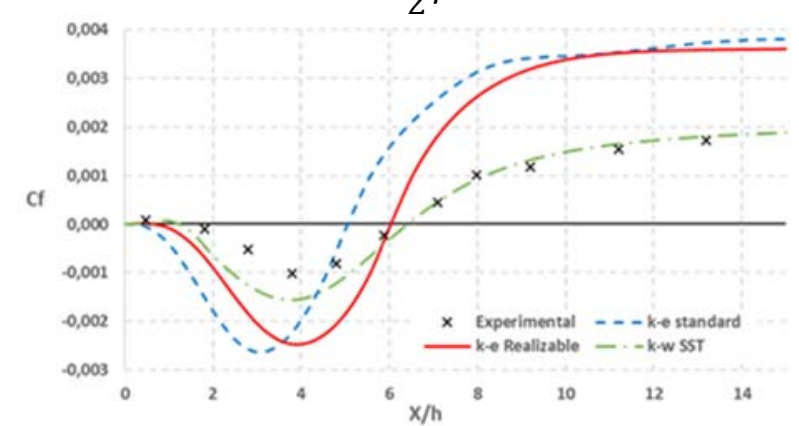

Figure 4. Cf trend on the lower wall as a function of $\mathrm{X} / \mathrm{h}$

Table 1. Reattachment lengths BFS case

\begin{tabular}{|c|c|}
\hline Turbulence model & $\begin{array}{c}\text { Reattachment length } \\
(\mathrm{Xr} / \mathrm{h})\end{array}$ \\
\hline Experimental $[15]$ & 6.26 \\
\hline $\mathrm{k}-\varepsilon$ standard & 5.06 \\
\hline $\mathrm{k}-\varepsilon$ Realizabile & 6.04 \\
\hline $\mathrm{k}-\omega$ SST & 6.42 \\
\hline
\end{tabular}

The position of the control sections for the vertical profiles is shown in Figure 5: inside the separation zone $(X / h=2)$, in the area near the reattachment of the bubble $(\mathrm{X} / \mathrm{h}=6)$ and in the area immediately downstream of it $(\mathrm{X} / \mathrm{h}=7)$.

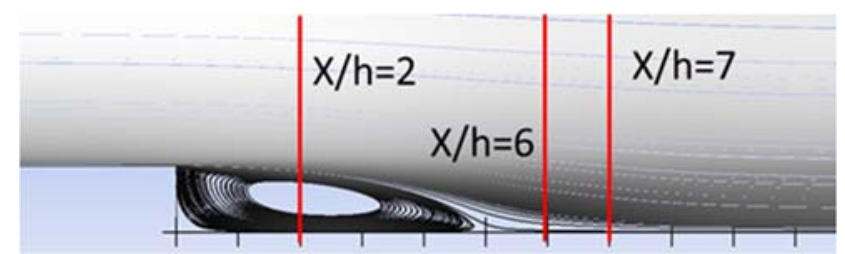

Figure 5. Control sections for BFS case
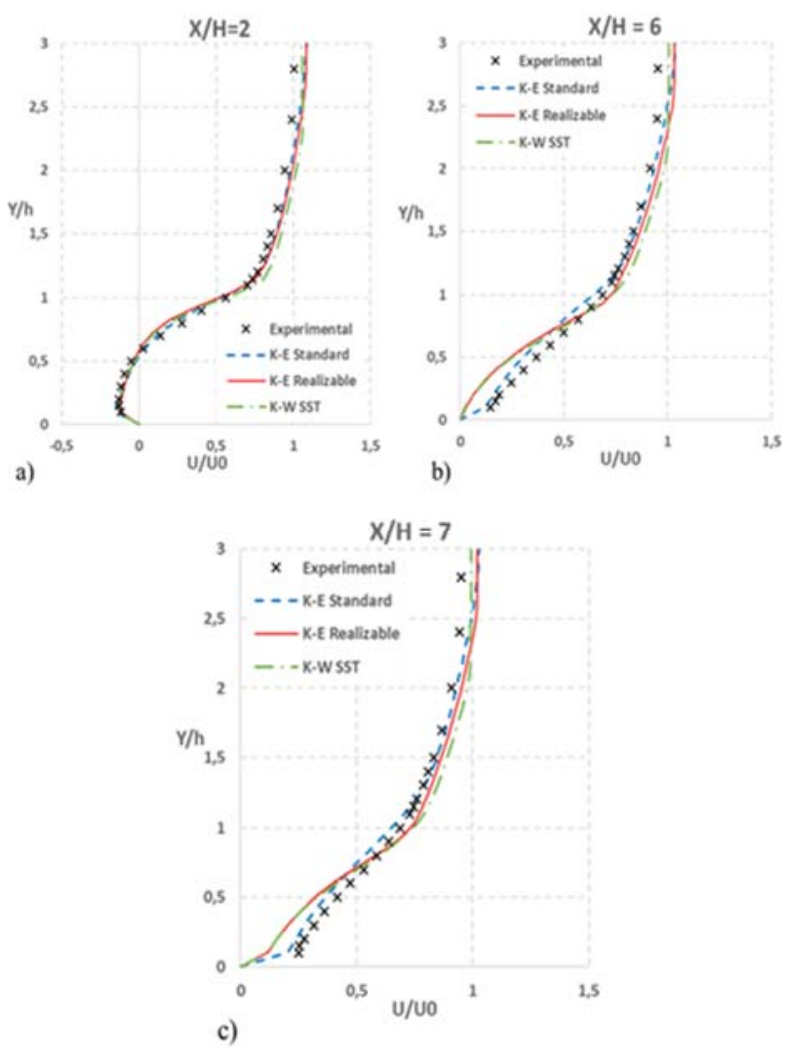

Figure 6. Dimensionless velocity profiles as a function of the $\mathrm{Y} / \mathrm{h}$ for the sections a) $\mathrm{X} / \mathrm{h}=2-\mathrm{b}$ ) $\mathrm{X} / \mathrm{h}=6$ - c) $\mathrm{X} / \mathrm{h}=7$.

Figure 6 shows the comparison of axial velocity profile distributions. Inside the separation zone (Fig. 6a) there is a good match between the results of the three simulations and the experimental case. In the other positions, Fig. 6 b-c, the k- $\varepsilon$ standard is the model that best approximates the experimental data. In Fig.7 the tangential stress profiles (-uv) are compared and the standard k-epsilon model remains the least accurate with respect to the experimental data. The simulation results with the k- $\omega$ SST model, on the other hand, are significantly in better match in all sections.

It can be concluded that the turbulence model that gives the best compromise is the k- $\omega \mathrm{SST}$, even if in terms of mean flow field is not the most accurate.

\subsection{Forward Facing Step (FFS)}

Using the same geometry and mesh of the BFS case, the FFS was studied taking as reference data the paper by Hattori \& Nagano [16]. It should be noted that in this case the reference data are from a Direct Numerical Simulation (DNS) simulation applied to the case of FFS and not from experimental investigation. The simulations were carried out at the same value of $R e=3000$. 

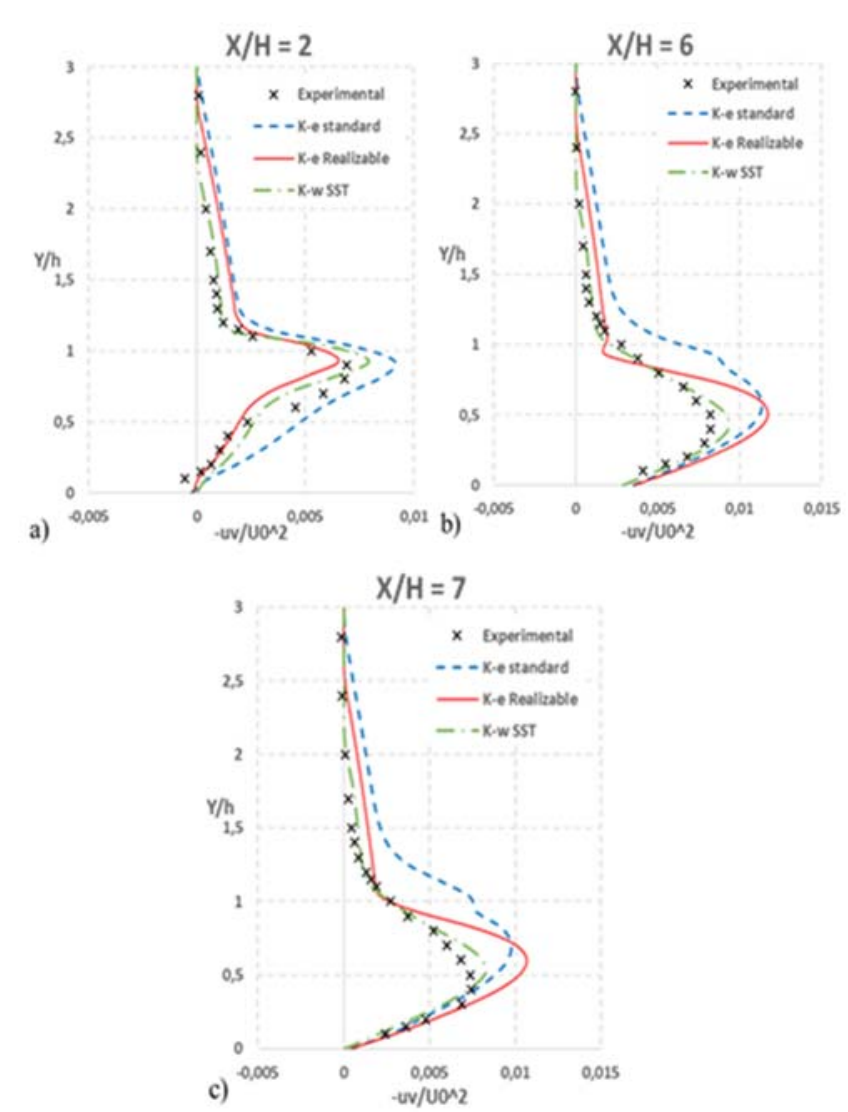

Figure 7. Tangential stress profiles as a function of the $\mathrm{Y} / \mathrm{h}$ for the sections a) $\mathrm{X} / \mathrm{h}=2-\mathrm{b}) \mathrm{X} / \mathrm{h}=6-$ c) $\mathrm{X} / \mathrm{h}=7$.

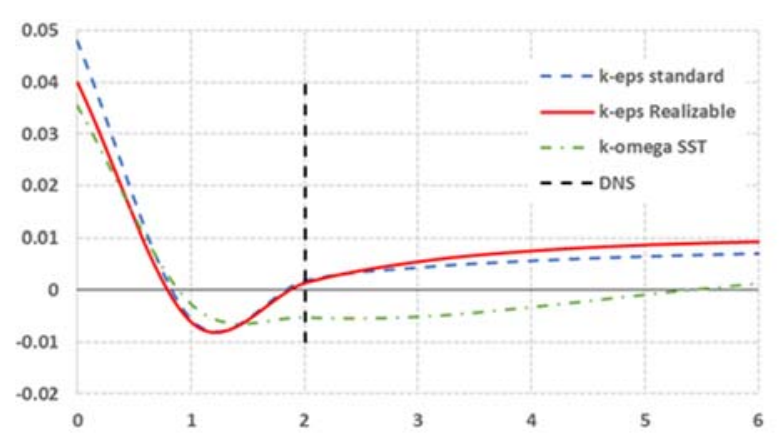

Figure 8. Cf trend on the lower wall as a function of $\mathrm{X} / \mathrm{h}$.

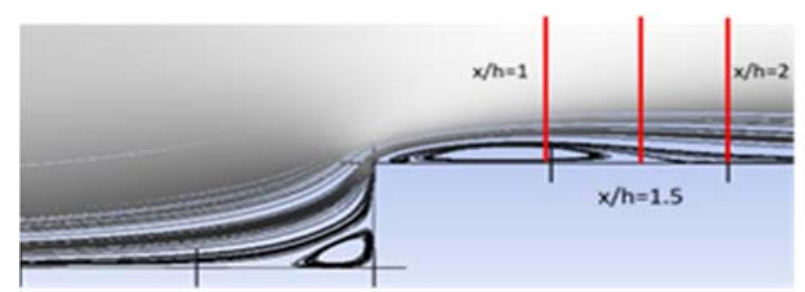

Figure 9. Control sections FFS case

As shown in Fig. 9 the flow in this case is subject to two separation zones: before the step and after the step. Three control sections, shown in Fig.9, have been considered in analogy to the previous case. The evaluation criteria of the turbulence model are the same as in the previous case.

Tab.2. Reattachment lengths FFS case

\begin{tabular}{|c|c|}
\hline Turbulence closure & $\begin{array}{c}\text { Reattachement point } \\
(\mathrm{X} / \mathrm{h})\end{array}$ \\
\hline DNS [16] & 2.01 \\
\hline $\mathrm{k}-\varepsilon$ standard & 1.84 \\
\hline $\mathrm{k}-\varepsilon$ realizabile & 1.88 \\
\hline $\mathrm{k}-\omega \mathrm{SST}$ & 5.40 \\
\hline
\end{tabular}
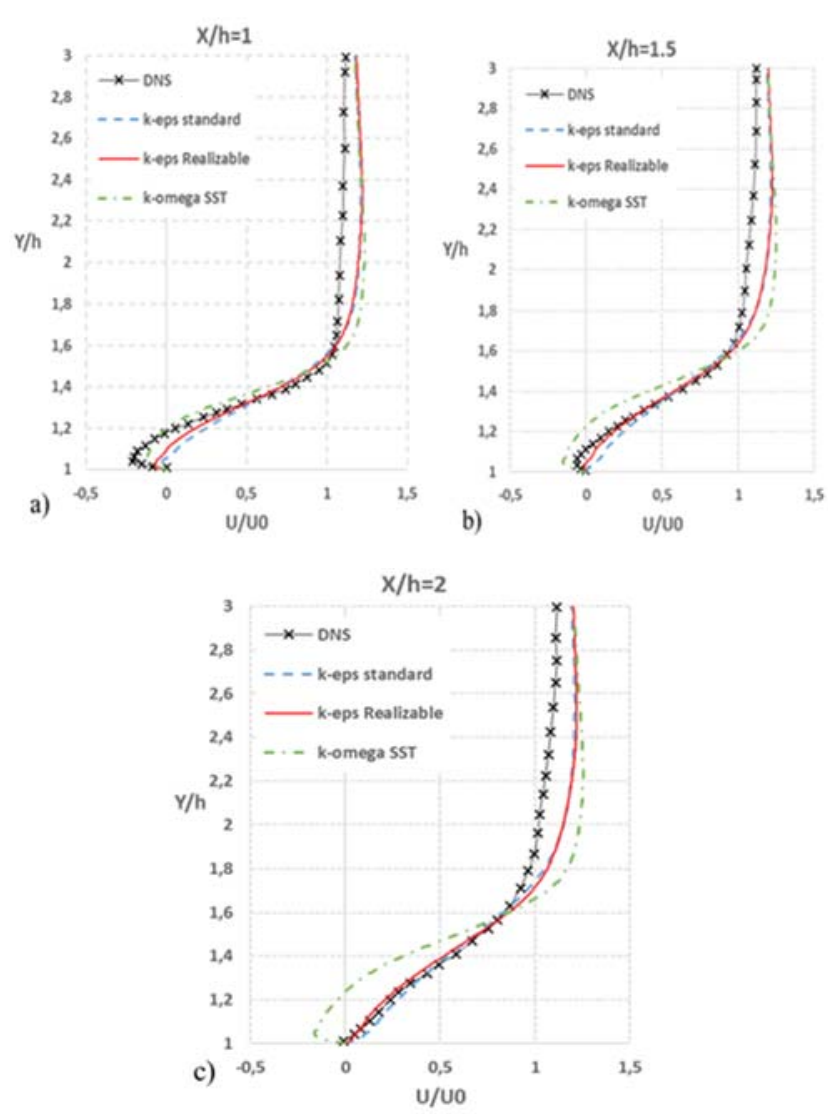

Figure 10. Dimensionless velocity profiles as a function of $\mathrm{Y} / \mathrm{h}$ for the sections a) $\mathrm{X} / \mathrm{h}=1.0-\mathrm{b}$ ) $\mathrm{X} / \mathrm{h}=1.5$ - c) $\mathrm{X} / \mathrm{h}=2.0$.

The comparison of the Skin friction factor $(\mathrm{Cf})$ is used to estimate the extent of the recirculation zone. Figure 8 represents the trend of $\mathrm{Cf}$ and highlights the DNS reattachment length compared to the simulation results. To identify the $\mathrm{Xr}$, the same principle used for the BFS case is adopted.

Table 2 shows the reattachment length values; it can be seen that both results of standard and Realizable k-epsilon models are closer to the DNS. Regarding the SST model, it clearly overestimates the length. This could be explained by the limiting factor in the production of turbulent kinetic energy in the SST model that is too high: reducing $\mathrm{k}$ the flow reattaches further down. From the dimensionless velocity 
profiles of Figure 10, it can be noticed that inside the separation zone the results of the SST model are closer to the reference datum (Fig.10.a). However, in the other two sections, the simulations with the kepsilon model, especially the Realizable, have a better match with the DNS. In the profile at $\mathrm{X} / \mathrm{h}=2$ (Fig.10.c) the SST case is still strongly separated.

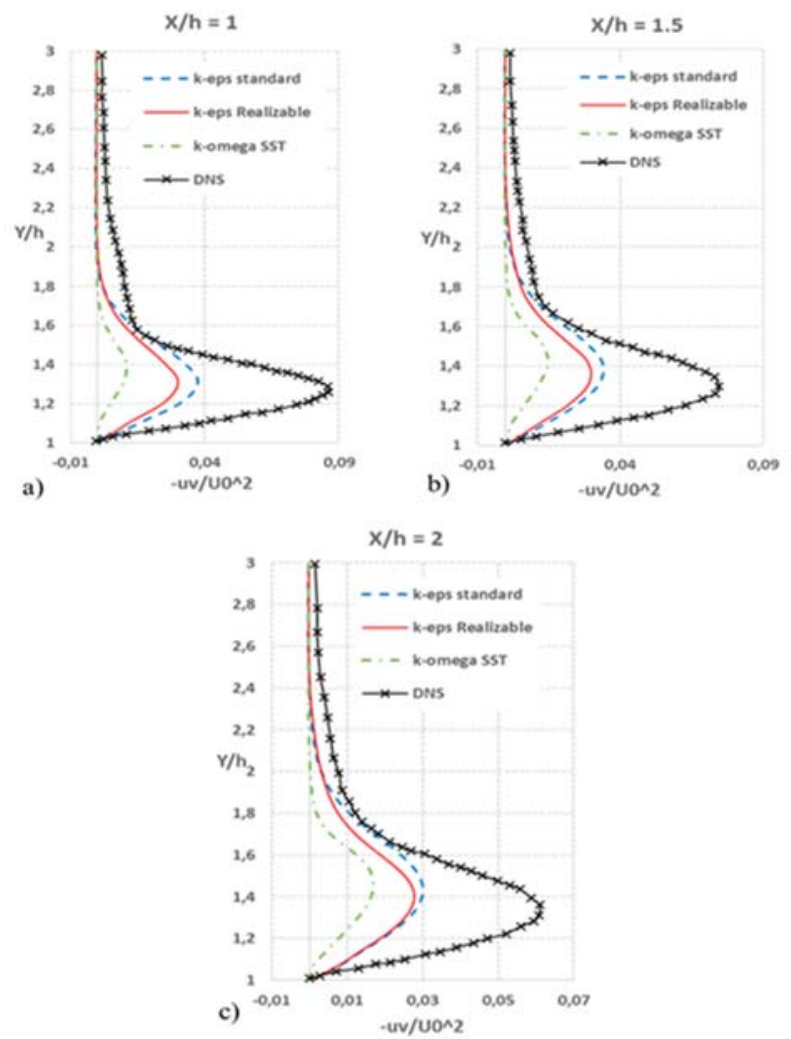

Figure 11. Tangential stress profiles as a function of the $\mathrm{Y} / \mathrm{h}$ coordinate for the sections a) $\mathrm{X} / \mathrm{h}=2-\mathrm{b}$ ) $\mathrm{X} / \mathrm{h}=6$ - c) $\mathrm{X} / \mathrm{h}=7$.

The difference between the models is also detected in the profiles of the tangential stress reported in Figure 11. The k-epsilon models are closer to the reference data from the DNS.

From the above detailed analysis for both reference cases it emerges that the k-epsilon Realizable model can be considered a good compromise solution for its accuracy with respect to the reference data both in terms of reattachment length, and of the mean flow field and turbulence quantities. It has been therefore selected for the analysis of the changes in the geometry of the edges.

\section{Effects of blunt or rounded edges in the forward and backward facing steps on the recirculating flow reattachment length}

In order to evaluate the effects on the separation extension of the flow at intersecting walls of rounding off the edges or making them blunt, a series of simulations has been performed for BFS and FFS with modified edges. Four geometries with blunt edges and other four geometries with rounded edges were evaluated starting from the reference case with sharp edge. In Fig. 12 the rounded and blunt edge definition with respect to the sharp edge case is reported. From a given step h, the following ratios of $\mathrm{r} / \mathrm{h}$ for the rounded cases have been considered: 0.01 , $0.05,0.1,0.15$; the corresponding cases with blunt configuration have been obtained from the rounded cases as defined in Fig.12. Unstructured meshes have been generated with the same criteria and parameters of the reference cases and the k-epsilon Realizable has been set. The same set of boundary conditions as for the reference cases have been used.

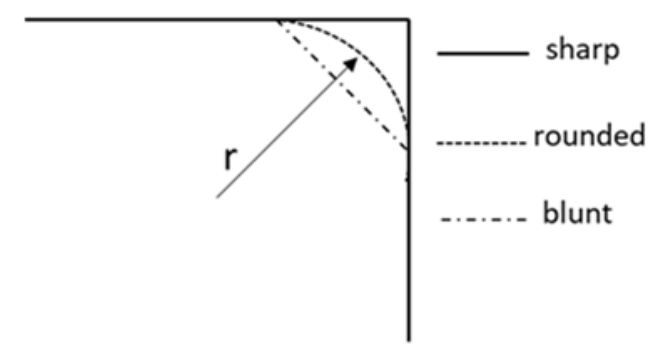

Figure 12. Edge geometrical modifications

The length of reattachment for the separation bubble in the BFS case are reported in Table 3 for both rounded and blunt cases. The above numerical data are shown in Figure 13 a) and b) for the blunt and rounded edge case respectively. It can be observed that increasing the rounding ratio $(\mathrm{r} / \mathrm{h})$ the separation zone is shortened, being the reattachment point closer to the edge.

Table 3. Reattachment lengths for blunt and rounded edges - BFS case.

\begin{tabular}{|c|c|c|}
\hline $\begin{array}{c}\text { Bending ratio } \\
(\mathrm{r} / \mathrm{h})\end{array}$ & $\begin{array}{c}\text { Reattachment } \\
\text { length blunt } \\
(\mathrm{Xr} / \mathrm{h})\end{array}$ & $\begin{array}{c}\text { Reattachment } \\
\text { length rounded } \\
(\mathrm{Xr} / \mathrm{h})\end{array}$ \\
\hline 0 & 6.04 & 6.04 \\
\hline 0.01 & 5.96 & 5.93 \\
\hline 0.05 & 5.56 & 5.82 \\
\hline 0.10 & 5.55 & 5.74 \\
\hline 0.15 & 5.41 & 5.59 \\
\hline
\end{tabular}

The blunt and the rounded cases have a different behaviour. With a blunt edge a saturation effect of the geometrical modification on the separation bubble is observed: the increase of the edge modification beyond a certain value $(\mathrm{r} / \mathrm{h}=0.10)$ does not significantly affects the separation bubble extension. 
With a corresponding rounded edge the above saturation effect is absent and the increase of the edge rounding off has a monotonic effect on the separation bubble reduction.

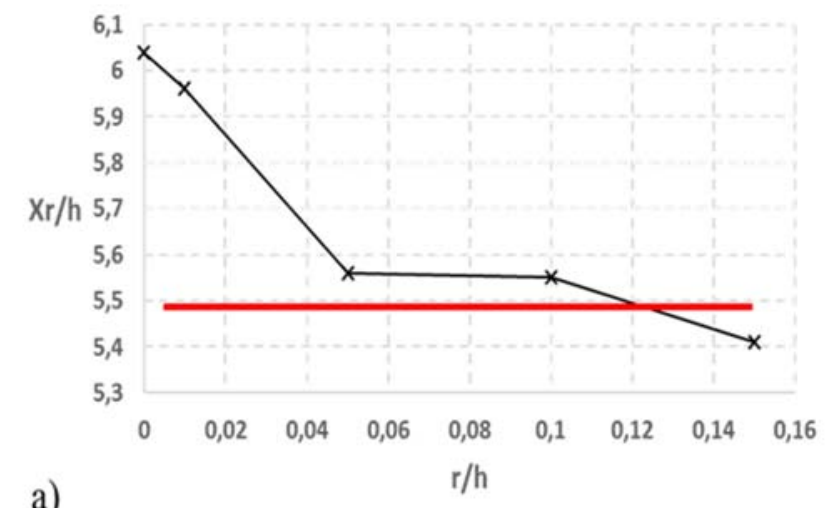

a)

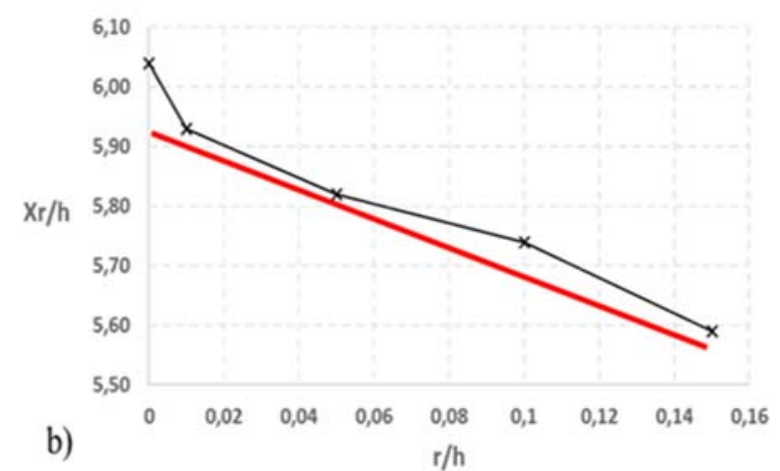

Figure 13. Reattachment length vs bending ratio $\mathrm{r} / \mathrm{h}$ of the edge a) blunt $-b$ ) rounded - BFS case.

The same edge modifications have been adopted for the FFS case and the results for both blunt and rounded edges are reported in Table 4 for the separation reattachment length. The separation zone on the upper part of the edge (see Figure 8) is considered. The numerical data are shown in Figure 14 a) and b) for the blunt and rounded edge case respectively. As for the BFS case the blunt edge has a saturation effect on the separation extension and a monotonic trend is present with rounded edge. In this case it must be observed that with a value of $\mathrm{r} / \mathrm{h}=0.15$ the separated zone is absent.

Table 4. Reattachment lengths for blunt and rounded edges - FFS case.

\begin{tabular}{|c|c|c|}
\hline $\begin{array}{c}\text { Bending ratio } \\
(\mathrm{r} / \mathrm{h})\end{array}$ & $\begin{array}{c}\text { Reattachment } \\
\text { length blunt } \\
(\mathrm{Xr} / \mathrm{h})\end{array}$ & $\begin{array}{c}\text { Reattachment } \\
\text { length rounded } \\
(\mathrm{Xr} / \mathrm{h})\end{array}$ \\
\hline 0 & 1.88 & 1.88 \\
\hline 0.01 & 1.24 & 1.12 \\
\hline 0.05 & 0.82 & 0.55 \\
\hline 0.1 & 0.54 & 0.37 \\
\hline 0.15 & 0.48 & 0 \\
\hline
\end{tabular}
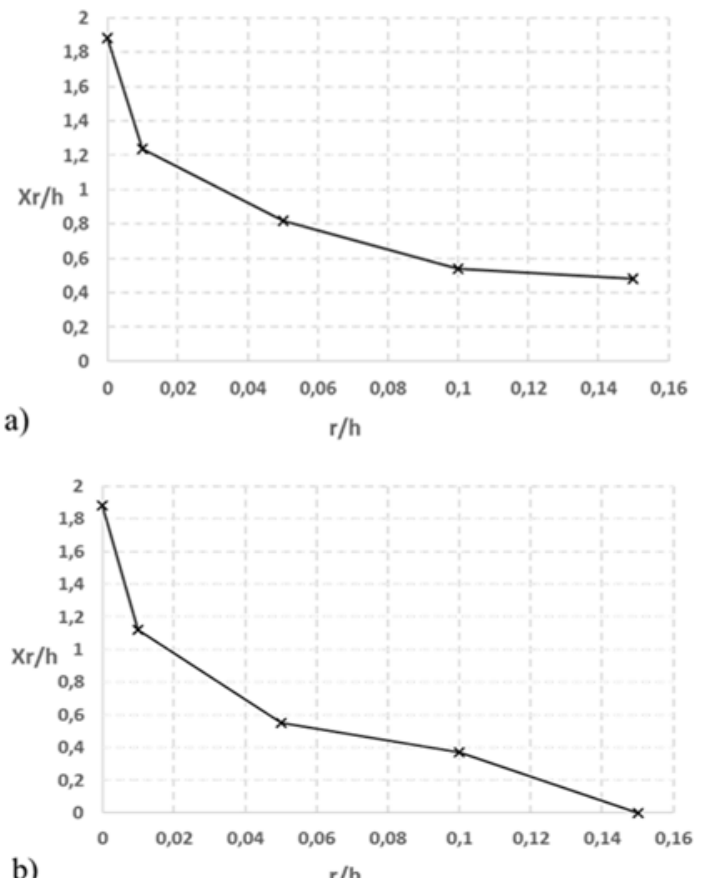

Figure 14. Reattachment length vs bending ratio $\mathrm{r} / \mathrm{h}$ of the edge a) blunt - b) rounded - FFS case.

The above results are very interesting because they highlight and quantify the effect of the edge modification on the flow structure; moreover, different behaviours for blunt or rounded cases are evident. The blunt edge is the situation that will be found in the new furnace system configuration (Figure1 left) while rounded edges are to be expected after the erosion effects during furnace service (Figure 1 right). The local flow acceleration and related pressure gradient induced by the edge configuration determine the boundary layer evolution and its separation extension with the above overall effects. It can be argued that the flow structure inside the system components will change starting from the brand new installation to the geometrical layout after some year of continuous operation. In the following paragraph, the application of the above concepts is shown for a crucial part of the furnace thermal system: the top part of the regenerative chamber.

\section{Effects of blunt or rounded edges on the flow structure in a $3 \mathrm{D}$ model of glass furnace regenerative system}

The effects of modified edges on a real geometry of a regenerative chamber setup are investigated. The 3D model shown in Figure 15a is considered; it consists of the following sub-domains: portion of the combustion chamber, port neck (channel connecting the combustion chamber with the regenerative 
tower), top of regenerative chamber, the checkers zone of the regenerative chamber (includes the bricks, made of refractory material, for the heat recovery process).

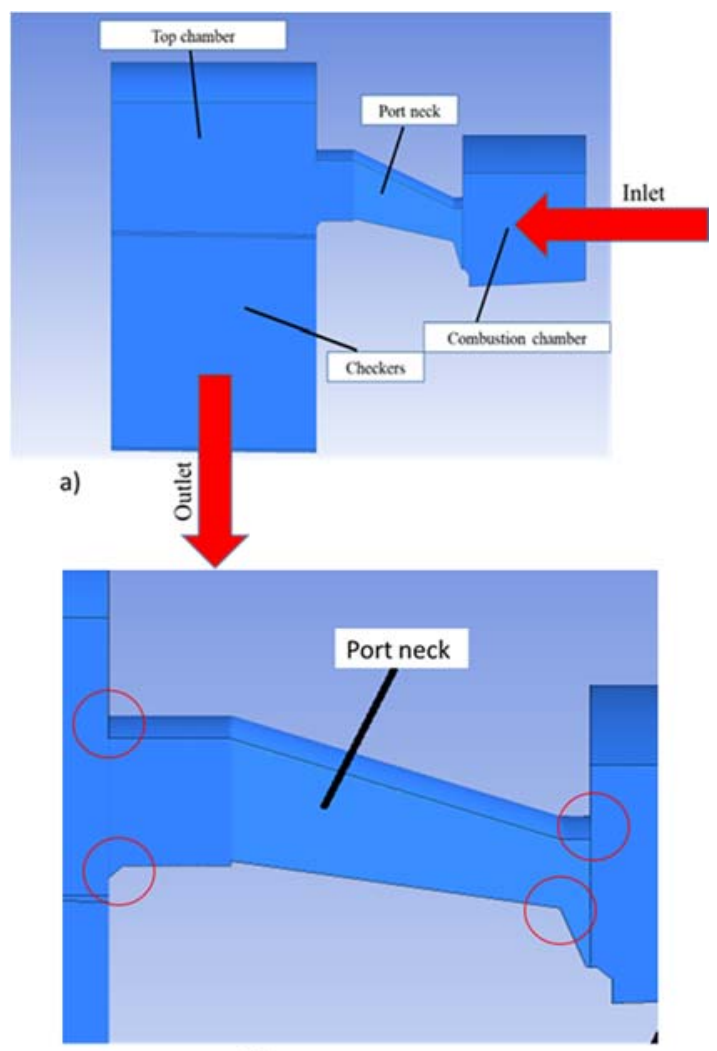

b)

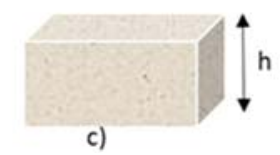

Figure 15. a) fluid domain - b) modified edges on the $3 \mathrm{D}$ geometry $-\mathrm{c}$ ) reference brick

Also in this case the commercial Ansys Fluent software has been used for the simulations, with the same finite volume approach.

The so-called hot phase of the regenerative process is considered [6,8]: the exhaust gases from the combustion chamber enter the port neck and flow through the regenerative chamber to transfer their heat content to the refractory system (that will preheat the combustion air in the following "cold phase" of the regenerative process). A crucial design requirement for this system is the flow uniformity at the top surface of the checker domain in order to have a uniform distribution of gases through the regenerative part of the chamber. The geometrical details of the port neck and its connection edges to the other components affects the flow structure and the flow evolution to the top of the regenerative chamber. In the present exercise, the top part of the domain (Combustion Chamber, Port Neck and Top
Chamber) has been simulated in three different geometrical configurations with different edges layout: sharp, blunt, rounded. In Figure 15b a meridional section of the domain is shown where the edges under investigation are visible. The height $h$ of the brick is considered to define the bending ratio $\mathrm{r} / \mathrm{h}$ as for the analysis on the $2 \mathrm{D}$ cases. A ratio $\mathrm{r} / \mathrm{h}=0.05$ is used for blunt edges and $\mathrm{r} / \mathrm{h}=0.1$ for rounded edges. Unstructured meshes have been generated for the top part of the domain. In the checker zone a regular structured mesh is used and the porous domain approach is setup to take into account both heat transfer and flow resistance effects due to the checkers assembly [5-8] In Figure 16 a section of the mesh is shown.

The thermal non-equilibrium model to simulate the heat transfer from the exhaust gases and the checkers in the porous domain has been used [7]. The Realizable k-epsilon turbulence model has been adopted as for the 2D analysis.

An operating point of 120 ton/day of glass production is considered for the furnace and the boundary conditions of exhaust gas massflow rate and temperature are set accordingly. The exhaust gases are a composition of ideal gases and the species transport model has been activated into the CFD simulation [5].

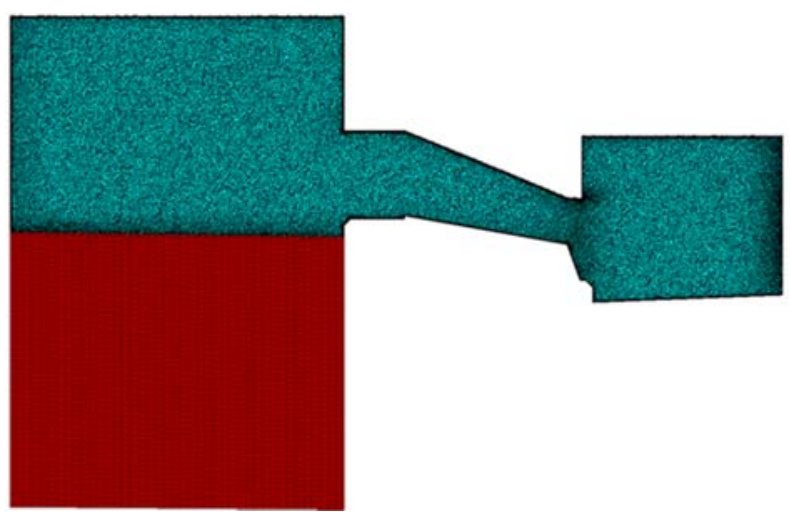

Figure 16. Mesh section for the regenerative chamber case

In Figure 17 the distributions of the velocity vectors on a longitudinal mid-section of the domain are shown for the three cases: a) sharp edges, b) blunt edges, c) rounded edges. The exhaust gases flow from left (combustion chamber outlet) to the right and enter the checkers zone (only a portion of the regenerative chamber is shown). Very different flow structures are observed. The sharp edges case is dominated by a massive recirculation zone that develops from the upper edge at the port neck inlet section; a strong jet if formed due to the massflow redistribution inside the port neck. In the blunt edges case a flow recirculation is still present at the upper 
part of the port neck but it has been dramatically reduced by the edge configuration. The above separation is eliminated by the higher local flow speed in the rounded edges case.
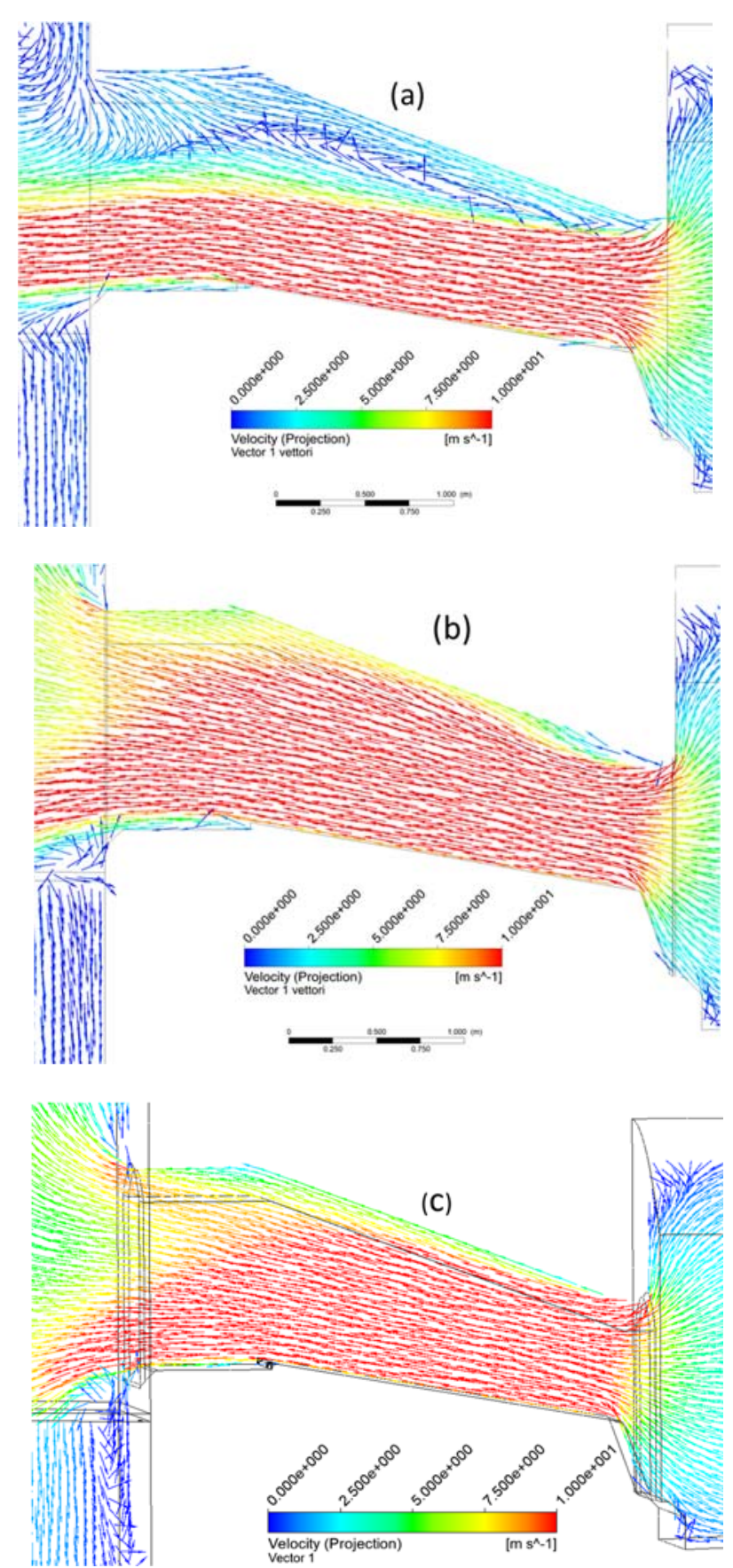

Figure 17 Velocity vectors inside the port neck with (a) sharped edges, (b) blunt edges and (c) rounded edges.

In Figure 18 the flow inside the top chamber domain is shown and the typical structure is observed: the jet flow from the port neck impinges to the bottom wall of the regenerative chamber and forms a recirculating macro structure that feeds the downstream part of the chamber with the checkers. The change of the flow structure in the port neck has a direct impact on the flow distribution at the entrance of the checkers.

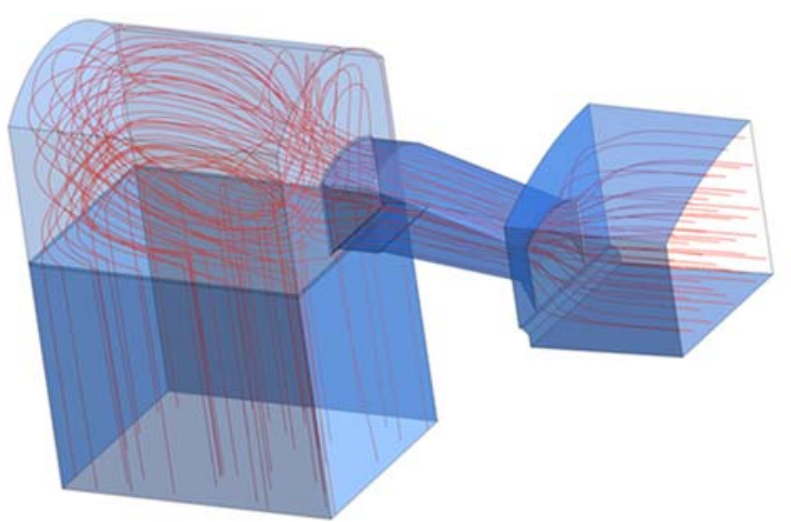

Figure 18. Flow structure inside the chamber

To assess the uniformity of the flow entering the checkers, the surface is divided into a set of macro cells where the flow data are averaged as a post processing from the CFD analysis (Figure 19).

\begin{tabular}{|l|l|}
\hline 10 & 20 \\
\hline 9 & 19 \\
\hline 8 & 18 \\
\hline 7 & 17 \\
\hline 6 & 16 \\
\hline 5 & 15 \\
\hline 4 & 14 \\
\hline 3 & 13 \\
\hline 2 & 12 \\
\hline 1 & 11 \\
\hline \multicolumn{2}{|c|}{ port neck } \\
\hline
\end{tabular}

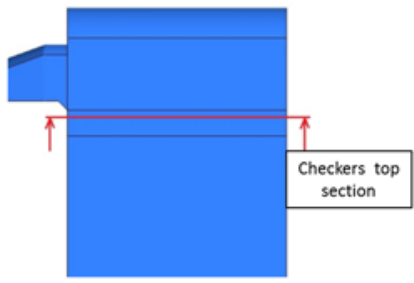

Figure 19. Top checkers section position and top chamber subdivision into macro cells

Figure 20 shows the flow distributions for the different simulated cases at the top surface of the checkers domain. For every macro cell the massflow rate percentage with respect to the total mass flow entering the checkers is evaluated (eq.4).

$$
m_{p c}=\frac{m_{i}}{m_{\text {tot }}} 100
$$

In order to highlight the flow non-uniformity a parameter as the average standard deviation with respect to the mean value has been introduced (eq.5). The standard deviation of the local mass flow rate through the first checker layer is used to compare the different flow structures at the above control section. High values of standard deviation are evidence of bad local flow uniformity. 


$$
\text { Average Std. Dev. }=\sqrt{\frac{\sum_{i=1}^{n}\left(m_{i}-\bar{m}\right)}{n-1}}
$$
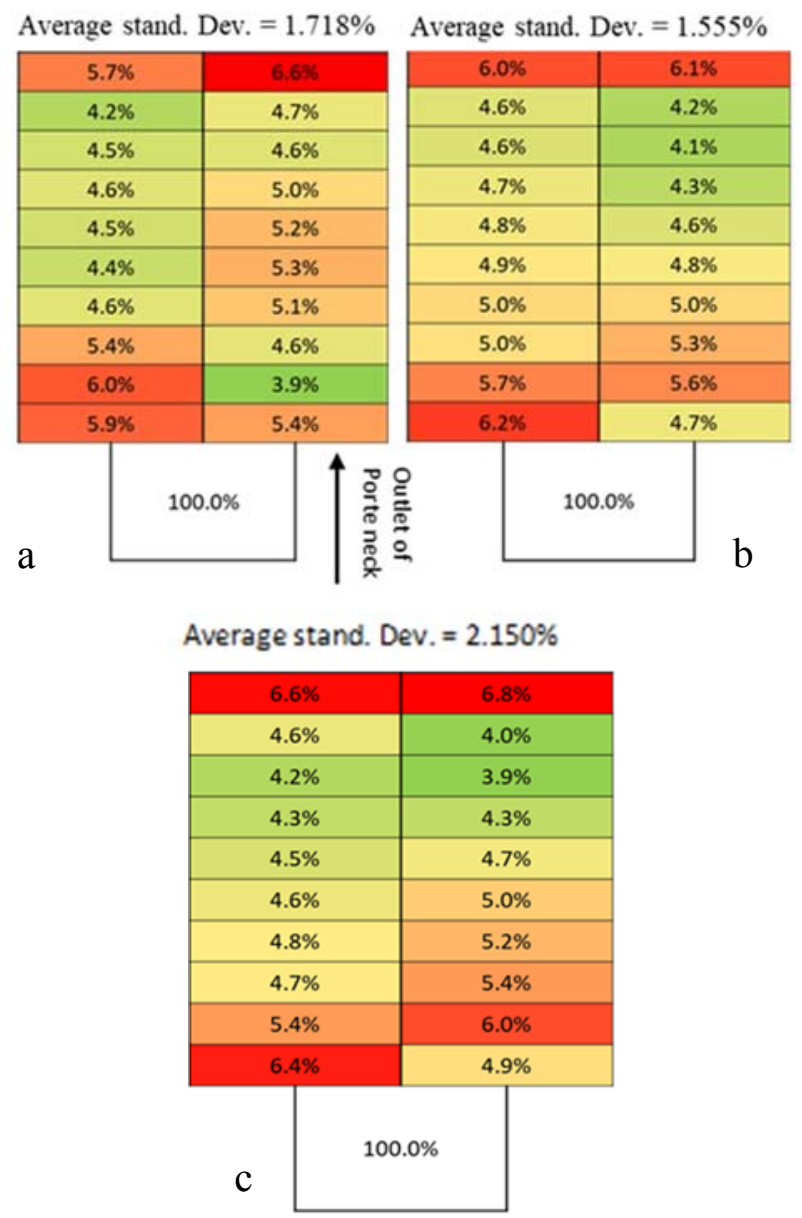

Figure 20. mass flow rate distribution and standard deviation values at top checkers section: (a) sharped edges, (b) blunt edges, (c) rounded edges.

All the cases have a high value of deviation at the bottom surface due to the flow impingement from the port neck jet (Figure 18). An improved flow uniformity is observed in the blunt edges case (Figure $20 \mathrm{~b})$ with respect to the sharp edges case (Figure 20a). The blunt edge is the reference configuration for the actual furnace with brand new refractories (Figure 20a). The above results highlight that the CFD model with blunt edges can be considered more representative of the actual flow structure inside the system instead of the sharp edges case (standard simplified CFD approach). A significant flow nonuniformity is observed in the rounded edges case (Figure 20c) where local and average higher values of standard deviation for the mass flow distribution are obtained. This is due to the local acceleration of the flow at the rounded edge that has an impact on the flow structure; this is evident at the bottom wall (where a stronger jet impinges) and in the region close to the first part of the chamber.

This model is representative of the system where corrosion effects are already evident; they cause a flow redistribution, with respect to the new configuration (blunt edges), with lower system performance due to the higher flow non-uniformity inside the chamber. The above effects will increase with the system aging.

\section{Conclusion}

A detailed 2D analysis on reference test cases from literature of BFS and FFS has been performed to set the CFD approach that is most accurate for recirculation zone prediction. Taking into account the intrinsic limits of the RANS approach and the steady analysis, the k- $\varepsilon$ Realizable turbulence model was identified as the best compromise to obtain accurate results in both step configurations. The CFD approach has been used to investigate the effects of step modification to the flow structure. Different results are obtained for blunt or rounded edges. In the former case, a saturation effect of the $\mathrm{r} / \mathrm{h}$ parameter is observed with respect to the separation extension for both BFS and FFS. In the latter case the separation extension has a monotonic reduction with the increase of $\mathrm{r} / \mathrm{h}$ for both BFS and FFS cases; moreover for higher values (from $\mathrm{r} / \mathrm{h}=0.15$ ) the separation in the FFS is absent. The interest is on the application of CFD to glass production plants with special focus on the regenerative chamber system; in this application, the blunt edge case is representative of the furnace with new refractory bricks while the rounded edges are present in the furnace after some time of operation due to erosion effects on the refractories. The application of the edge modifications to a reference $3 \mathrm{D}$ model of a regenerative chamber has clearly showed that the "ideal" CAD model from design standards with sharp edges gives unrealistic flow structures inside the components due to massive flow separations induced by the sharp edge. The attention to blunt edge details must be considered for the routinely use of CFD technology to correctly support the system design and to be a reliable tool for parametric analyses and design development for new and improved configurations. The introduction of rounded edges in the 3D CFD model will allow the development of models for the prediction of performance variation due to aging.

\section{References:}

[1] Zarrinehkafsh, M.T.; Sadrameli, S.M. Simulation of fixed bed regenerative heat 
exchangers for flue gas heat recovery. Appl. Therm. Eng.2004, 24, 373-382.

[2] Reboussin, Y.; Fourmigu, J.F.; Marty, P.; Citti, O. A numerical approach for the study of glass furnace regenerators. Appl. Therm. Eng. 2005, 25, 2299-2320.

[3] Koshelnik, A.V. Modelling operation of system of recuperative heat exchangers for aero engine with combined use of porosity model and thermo-mechanical model. Glass Ceram. 2008, 65, 301-304.

[4] Cravero, C.; De Domenico, D.; Leutcha, P.J.; Marsano, D.; Strategies for the Numerical Modelling of Regenerative Pre-heating Systems for Recycled Glass Raw Material. IEETA Mathematical Modelling of Engineering Problems. Vol.6, No.3, 2019, 324-332.

[5] D. Basso, C. Cravero, A.P. Reverberi, B. Fabiano CFD Analysis of Regenerative Chambers for Energy Efficiency Improvement in Glass Production Plants Journal Energies 2015, 8(8), 8945-8961; doi:10.3390/en8088945, ISSN 1996-1073.

[6] Cogliandro, C. Cravero, M. Marini, A. Spoladore, Simulation strategies for regenerative chambers in glass production plants with strategic exhaust gas recirculation system, 11th AIGE 2017, 2nd AIGE/IEETA Int. Conf., 12-13 June 2017, Genova, Italy International Journal of Heat and Technology, ISSN 0392-8764, vol. 35 Special Issue 1, September 2017 pp S449-S445, DOI 10.18280/ijht.35Sp0161.

[7] C. Cravero, D. Marsano, Numerical Simulation of Regenerative Chambers for Glass Production Plants with a Non-Equilibrium Heat Transfer Model, presented at 13th International Conference on Energy, Environment, Ecosystems and Sustainable Development (EEESD '17), 27-27 January 2017, Rome (Italy), published on WSEAS Transactions on Heat and Mass Transfer, ISSN / E-ISSN: 1790-5044 /2224-3461, Volume 12, 2017, Art. \#3, pp. 2129;

[8] Cravero, C., De Domenico, D. (2019). The use of CFD for the design and development of innovative configurations in regenerative glass production furnaces. Energies, 2019, 12(13):2455.

[9] C.Cravero, A.Satta, A CFD model for real gas flows, ASME Paper 2000-GT-0518, ASME Turbo Expo 2000, Munich (Germany), 8-11 May, 2000;.

[10] A.M. Guzmán, D.I. Martínez, R. González (2014). Corrosion-erosion wear of refractory bricks in glass furnaces, Engineering Failure Analysis 46 (2014) 188-195.

[11] Kim, J., Kline, S.J., Johnston, J.P. Investigation of a reattaching turbulent shear layer: flow over a backward-facing step, Journal of Fluids Engineering 102 (1980) 302-308.

[12] Eaton, J. K., Johnston, J. P., (1981). A review of research on subsonic turbulent flow reattachment. AIAA Journal 19, 1093-1100.

[13] Thangam, S., Speziale, C.G., Turbulent flow Pasta backward facing step: a critical evaluation of two equation models. AIAA Journal, Vol.30, No. 5, May 1992, 1314-1320.

[14] Sherry, M. J., Jacono, D. L., Sheridan, J., Mathis, R., \& Marusic, I. (2009). Flow Separation Characterisation of a Forward Facing Step Immersed in a Turbulent Boundary Layer. Sixth International Symposium on Turbulence and Shear Flow Phenomena, pp. 1325-1330.

[15] Driver, D.M., Seegmiller, H.L., (1985). Features of a reattaching turbulent shear layer in divergent channel flow. AIAA J. 23, 163-171.

[16] Hattori, H., Nagano, Y., (2010). Investigation of turbulent boundary layer over forward-facing step by means DNS. International Journal of Heat and Fluid Flow 31, 284-294.

[17] Langley Research Center, Turbulence modeling Resource website: https://turbmodels.larc.nasa.gov/backstep_val.h tml, last access 9/12/2019. 